\title{
Differences in nitric oxide airway diffusion after maximum oxygen uptake test in asthmatic and nonasthmatic elite junior cross-country skiers
}

\author{
Marieann Högman ${ }^{1}$, Lars Wedholm²,3 ${ }^{2}$ Tomas Carlsson ${ }^{3}$, Magnus Carlsson ${ }^{3}$ and \\ Michail Tonkonogi ${ }^{3}$
}

Affiliations: ${ }^{1}$ Dept of Medical Sciences, Respiratory, Allergy and Sleep Research, Uppsala University, University Hospital, Uppsala, Sweden. ${ }^{2}$ Dept of Medicine, Falun Hospital, Falun, Sweden. ${ }^{3}$ School of Education, Health and Social Studies, Dalarna University, Falun, Sweden.

Correspondence: Marieann Högman, Dept of Medical Sciences, Respiratory, Allergy and Sleep Research, Uppsala University, University Hospital, S 75185 Uppsala, Sweden. E-mail: marieann.hogmanamedsci.uu.SE

ABSTRACT Asthma is common in cross-country skiers and is often treated with $\beta_{2}$-agonists and inhaled corticosteroids (ICS). Exhaled nitric oxide (NO) is often used to guide ICS treatment in asthma. This study investigated the change in pulmonary $\mathrm{NO}$ dynamics before and after a maximum oxygen uptake $\left(V_{\mathrm{O}_{2} \max }^{\prime}\right)$ test.

An extended NO analysis was performed among Swedish elite junior cross-country skiers $(\mathrm{n}=25)$, with and without declared asthma, before and after a $V^{\prime} \mathrm{O}_{2} \max$ test using roller skis. Asthma was declared by six boys and two girls among whom five occasionally used ICSs.

There were no differences in baseline NO parameters between those with and without declared asthma. The median (interquartile range) diffusion capacity over airway wall $\left(D_{\text {awNO}}\right)$ was $21(17-25) \mathrm{mL} \cdot \mathrm{s}^{-1}$, which is much increased for this age group. After the $V^{\prime}{ }_{\mathrm{O}_{2} \max }$ test, there were statistically significant differences from the baseline fraction of exhaled $\mathrm{NO}\left(F_{\mathrm{ENO}_{50}}\right)$, NO flux from airways, $D_{\text {awNO }}$ and alveolar NO values; but not in the NO content in airway wall $\left(C_{\mathrm{awNO}}\right)$ for all subjects together as one group. However, in the asthma group, differences were only seen in $F_{\mathrm{ENO}_{50}}$ and $C_{\mathrm{awNO}}$.

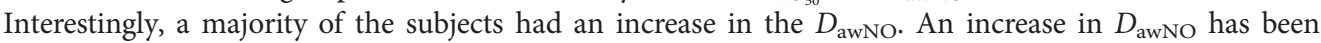

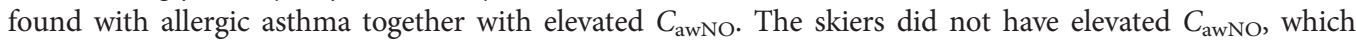
indicates an absence of inflammation in the airway wall. Modelling of lung NO production clearly shows that the asthma among our skiers is distinct from the allergic asthma in nonathletes.

@ERSpublications

NO pulmonary dynamics of junior cross-country skiers with asthma respond differently to the $V_{\mathrm{O}_{2} \max }^{\prime}$ test than in those without asthma. Analysis of airway inflammation should be considered before inhaled corticosteroids are prescribed. https://bit.ly/3eWB1JZ

Cite this article as: Högman M, Wedholm L, Carlsson T, et al. Differences in nitric oxide airway diffusion after maximum oxygen uptake test in asthmatic and nonasthmatic elite junior crosscountry skiers. ERJ Open Res 2021; 7: 00378-2020 [https://doi.org/10.1183/23120541.00378-2020].

Copyright OERS 2021. This version is distributed under the terms of the Creative Commons Attribution NonCommercial Licence 4.0. For commercial reproduction rights and permissions contact permissions@ersnet.org 


\section{Introduction}

Respiratory symptoms are common in elite athletes. The prevalence of asthma/airway hyperreactivity is as high as $15 \%$ [1]. In cross-country skiers, the prevalence is even higher. In a Swedish study among skiers that used a postal questionnaire, $29 \%$ in the age group 15-19 years self-reported physician-diagnosed asthma [2]. In another Swedish postal questionnaire study among adolescent skiers that also included control subjects, the prevalence of physician-diagnosed asthma was $23 \%$ among skiers and $12 \%$ in the control group [3]. Beta ${ }_{2}$-agonists and inhaled corticosteroids (ICS), which are asthma medications, are often used among skiers for the treatment of respiratory symptoms. According to a 2008 joint task force of the European Respiratory Society (ERS) and the European Academy of Allergy and Clinical Immunology, a diagnosis of exercise-induced asthma is not the same as exercise-induced bronchoconstriction (EIB), and most of the elite athletes referred for respiratory problems do not suffer from asthma [4].

Elite cross-country skiers are exposed to cold dry air, and with a minute volume around $200 \mathrm{~L}$ during training or competition, their airways will be challenged to heat and to humidify the air. Stress on the airway also entails inflammatory cell attraction. However, these cells do not seem to be activated [5] so low values of exhaled nitric oxide $\left(F_{\mathrm{ENO}}\right)$ can therefore be expected. It has been shown that $F_{\mathrm{ENO}}$ was not elevated in a group of skiers when compared to a group of people with asthma even though significant bronchial responsiveness to inhaled methacholine was present [6].

$F_{\text {ENO }}$ has been shown to decrease after a short exercise challenge [7], as well as after a marathon race [8]. A measurement of $F_{\mathrm{ENO}}$ at one flow will only reveal a sum of the changes in the pulmonary $\mathrm{NO}$ dynamics, whereas an extended NO analysis can localise specific NO parameter changes. When assessing pulmonary NO dynamics, the nonlinear method makes it possible to estimate the alveolar $\mathrm{NO}\left(C_{\mathrm{ANO}}\right)$, the airway flux of $\mathrm{NO}\left(\mathrm{J}_{\mathrm{awNO}}\right)$, the content of $\mathrm{NO}$ in the airway wall $\left(C_{\mathrm{awNO}}\right)$ and the diffusing capacity of $\mathrm{NO}$ $\left(D_{\text {awNo }}\right)$. Published $C_{\mathrm{ANO}}, C_{\mathrm{awNO}}$ and $D_{\mathrm{awNO}}$ data on winter sports athletes have not been found. This study investigated the pulmonary $\mathrm{NO}$ dynamics and the change before and after a maximum oxygen uptake $\left(V_{\mathrm{O}_{2} \max }^{\prime}\right)$ test in elite junior cross-country skiers.

\section{Material and methods}

Study design and subjects

Swedish elite junior cross-country skiers $(n=25)$ were recruited during their yearly check-up to determine their maximum oxygen uptake. Among these were 17 boys and 8 girls. Our sample was taken from the top performing cross-country skiers, which was $12 \%$ of the total 210 from this age group in Sweden. The Regional Review Board in Uppsala, Sweden (Dnr 2018/349) approved the study on 28 November 2018. All subjects gave written informed consent.

The subjects filled out a questionnaire regarding their health that contained questions about illnesses, medications, training, diet, hydration, current injuries as well as any heart, airway, dizziness, blood pressure, head trauma or allergy issues. Exhaled NO was analysed before and within 5-10 min after a $V^{\prime} \mathrm{O}_{2} \max$ test that used roller skis.

\section{Testing procedures}

An analyser (EcoMedics DLC 88; Eco Medics AG, Dürnten, Switzerland) was used to measure NO levels. Calibration and maintenance of the analyser was performed according to the manufacturer's instructions. The zero-point off-set was controlled before the measurements. The subjects' statures (Harpenden Stadiometer, Holtain Ltd., Crymych, UK) and body masses (Midrics 2, Sartorius AG, Göttingen, Germany) were measured before a standardised warm-up that consisted of $10 \mathrm{~min}$ of roller-skiing on a treadmill. The roller-skiing tests to determine the subjects' $V^{\prime}{ }_{\mathrm{O}_{2} \max }$ were performed on a motor-driven treadmill (Saturn 450/300 rs; h/p/Cosmos Sports \& Medical GmbH, Nussdorf-Traunstein, Germany). The subjects used the laboratory's roller skis (Pro-Ski C2; Sterners Specialfabrik AB, Dala-Järna, Sweden) and their own poles with plastic tips (black plastic tip; LEKI Lenhart GmbH, Kirchheim, Germany) provided by the laboratory. Throughout the $V^{\prime} \mathrm{O}_{2} \max$ test, variables of expired air were continuously analysed using a metabolic cart in the mixing-chamber mode (Jaeger Oxycon Pro, Erich Jaeger GmbH, Friedberg, Germany). Before each test, the expiratory flow meter and the $\mathrm{O}_{2}$ and $\mathrm{CO}_{2}$ analysers were calibrated according to the manufacturer's specifications. Capillary blood samples were collected from a fingertip at 2 and $5 \mathrm{~min}$ after the $V^{\prime} \mathrm{O}_{2} \max$ test. These samples were then analysed to determine blood lactate concentrations (Biosen 5140, EKF-diagnostic GmbH, Barleben, Germany). Within 10 min after the $V^{\prime} \mathrm{O}_{2}$ max test, the exhaled NO levels were re-analysed.

\section{NO analysis}

In conformity with the 2005 American Thoracic Society and the ERS recommendations for NO measurements, exhaled $\mathrm{NO}$ was analysed at an exhalation flow rate of $50 \mathrm{~mL} \cdot \mathrm{s}^{-1}\left(F_{\mathrm{ENO}_{50}}\right)$. In accordance 
FIGURE 1 The two-compartment model consists of the conducting airways and the gas exchange area. In the conducting airways, all airways of the lungs are equally represented. The gas exchange area contains the alveolar or acinar compartment as well as the respiratory bronchiole. When the alveolar gas with its low content of nitric oxide $(\mathrm{NO})\left(C_{\mathrm{ANO}}\right)$ is expelled, the contribution of NO from the airways is driven by a concentration gradient of NO from the airway wall $\left(C_{\text {awno }}\right)$. The rate is governed by the diffusion capacity of the airway wall $\left(D_{\text {awno }}\right)$. The airway NO flux $\left(J_{\text {awno }}\right)$ is therefore dependent on both the $C_{\text {awNo }}$ and the $D_{\text {awno. }}$. Exhaled NO $\left(F_{\mathrm{ENO}}\right)$ is dependent on all of the NO parameters.

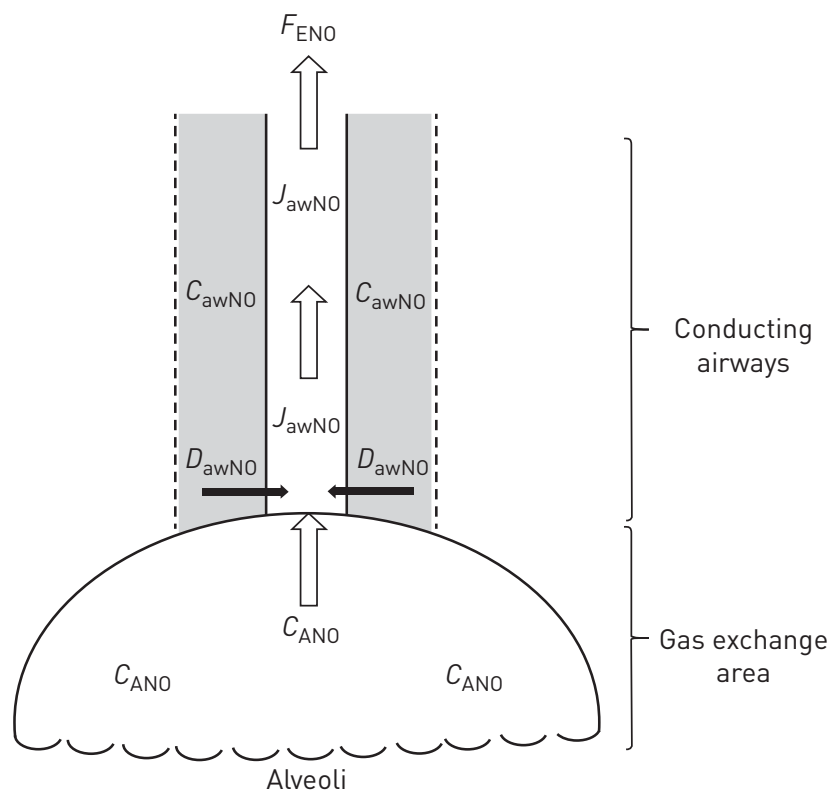

with the ERS technical standards of modelling NO dynamics, two methods were used: the nonlinear method with exhalation flows of 20,100 and $300 \mathrm{~mL} \cdot \mathrm{s}^{-1}$, and the linear method with exhalation flows of 100,200 and $300 \mathrm{~mL} \cdot \mathrm{s}^{-1}$ [9]. Flow resistors were used with the subjects to facilitate a constant exhaled flow. A visual feedback system was used to guide the subjects so that they could achieve the targeted flow throughout the exhalation. The Högman-Meriläinen algorithm (HMA) nonlinear method and the Tsoukias and George linear method (TG) [9] were both used with the software in the NO analyser. For quality control, a calculated $F_{\mathrm{ENO}_{50}}$ for the HMA and an r-value for the linearity of the TG method were derived for each subject on the two NO analysis occasions. The HMA method estimates the following NO parameters: $C_{\mathrm{ANO}}, C_{\mathrm{awNO}}, D_{\mathrm{awNO}}$ and $J_{\mathrm{awNO}}$, whereas the TG method only estimates $C_{\mathrm{A}} \mathrm{NO}$ and $J_{\mathrm{aw}} \mathrm{NO}$. As they could find it difficult to breathe after the $V^{\prime}{ }_{\mathrm{O}_{2} \max }$ test and perform an exhalation at the low flow of $20 \mathrm{~L} \cdot \mathrm{s}^{-1}$, all of the subjects were to perform the HMA method and TG method on both test occasions. The two-compartment model of the lung NO dynamics is seen in figure 1 .

\section{Maximum oxygen uptake test}

The incremental treadmill roller-skiing test to determine the $V^{\prime} \mathrm{O}_{2} \max$ was begun using the diagonal-stride technique. During the initial $30 \mathrm{~s}$ of the test, the treadmill inclination was $2.4^{\circ}$ and the treadmill speeds were $9.0 \mathrm{~km} \cdot \mathrm{h}^{-1}$ for females and $10.9 \mathrm{~km} \cdot \mathrm{h}^{-1}$ for males. Thereafter, the inclination was increased by $0.4^{\circ}$ and the speed was increased by $0.1 \mathrm{~km} \cdot \mathrm{h}^{-1}$ every $30 \mathrm{~s}$ until volitional fatigue. The $V_{\mathrm{O}_{2} \max }^{\prime}$ was defined as the highest mean oxygen uptake during a 60 -s period when meeting the criterion of a plateau in oxygen uptake despite an increase in exercise intensity. Determination of the plateau was based on the recognition of data points that fell outside (and below) the extrapolated 95\% confidence interval for the $V^{\prime} \mathrm{O}_{2}$-work rate relationship [10]. In addition to the oxygen uptake plateau, a blood lactate concentration of $\geqslant 8 \mathrm{mmol} \cdot \mathrm{L}^{-1}$ was also required to confirm that the participant achieved $V^{\prime}{ }_{\mathrm{O}_{2} \max }$.

\section{Analysis}

All statistical analyses were performed using SPSS, version 26 for Windows (SPSS Inc., Chicago, MI, USA). Data are expressed as median (interquartile range). The Mann-Whitney U-test was used to make comparisons between any two groups. For pairwise comparisons the Wilcoxon signed-rank test was applied. Correlations were tested with Spearman's rank order correlation. A p-value of $<0.05$ was considered significant. Plots were made with SigmaPlot graphic software, version 14 for Windows (SYSTAT, Alfasoft AB, Göteborg, Sweden).

\section{Results}

Of the 25 elite junior cross-country skiers that participated, eight declared that they had asthma that was diagnosed by a physician. Of these, five occasionally used ICSs together with a $\beta_{2}$-agonist (short or long acting), one only used a short-acting $\beta_{2}$-agonist and two did not use any medication. Allergies (mite, furry animals, pollen or grass) were declared by seven subjects, four of whom had asthma that was treated with ICSs together with a $\beta_{2}$-agonist (short or long acting) and one that was treated with a short-acting 


\begin{tabular}{|c|c|c|c|c|}
\hline & All & Nonasthma & Asthma & $p$-value \\
\hline Subjects $\mathrm{n}$ & 25 & 17 & 8 & \\
\hline Age years & $18(17-20)$ & $19(17-20)$ & $18(17-19)$ & 0.75 \\
\hline Body mass index $\mathrm{kg} \cdot \mathrm{m}^{-2}$ & $22(21-24)$ & $22(22-23)$ & $22(21-26)$ & 0.84 \\
\hline$V_{0, \max }^{\prime} L \cdot \min ^{-1}$ & $4.25(3.77-4.79)$ & $4.25(3.74-4.80)$ & $4.20(3.77-4.79)$ & 0.93 \\
\hline$V_{0, \max }^{\prime} \mathrm{mL} \cdot \min ^{-1} \cdot \mathrm{kg}^{-1}$ & $60(55-64)$ & $60(55-66)$ & $61(52-64)$ & 0.80 \\
\hline Blood lactate mmol. $\mathrm{L}^{-1}$ & $12.7(11.7-14.6)$ & $12.7(11.7-14.1)$ & $12.7(11.1-16.2)$ & 0.67 \\
\hline Time to exhaustion min & $7.37(6.24-8.21)$ & $7.50(6.51-8.52)$ & $6.50(6.11-7.73)$ & 0.12 \\
\hline
\end{tabular}

$\beta_{2}$-agonist. All of the remaining three who declared allergies took an antihistamine. There were no statistically significant baseline differences in the NO parameters when comparisons were made between the nonasthma and the asthma groups, the nonallergic and the allergic groups and nonallergic asthmatic and the allergic asthmatic groups. Therefore, the subjects were divided into nonasthma $(n=17)$ and asthma $(n=8)$ groups. Subject characteristics are presented in table 1 . There were no differences in relation to age or body mass index between the nonasthma and asthma groups. For the $V^{\prime}{ }_{\mathrm{O}_{2} \max }$ test, all subjects used roller skies except for three male skiers who preferred to run. There was no statistically significant difference in their performance in regard to asthma. When those with asthma and allergy were treated as one group, their time to exhaustion was shorter than the nonasthma/nonallergy group: 6.72 (6.14-7.52) versus $7.96(6.91-8.79) \mathrm{min}, \mathrm{p}=0.002$.

All subjects were able to perform the HMA and TG methods on both test occasions. The quality control measurement results were well within the ERS standardisation recommendations [9]. For the HMA method, the calculated $F_{\mathrm{ENO}_{50}}$ in comparison to the measured $F_{\mathrm{ENO}_{50}}$ was $-1(-2,0) \mathrm{ppb}$, and the r-value for the TG method was $0.99(0.97-1)$. There was no difference in the estimation of $C_{\mathrm{ANO}}$ between the methods: 1.9 (1.6-2.4) and $1.9(1.3-2.3) \mathrm{ppb}$, respectively, $\mathrm{p}=0.71$. The estimation of $J_{\text {awNo }}$ using the HMA method was $0.63(0.33-0,90) \mathrm{nL} \cdot \mathrm{s}^{-1}$, and with the TG method $0.67(0.50-1.0) \mathrm{nL} \cdot \mathrm{s}^{-1}, \mathrm{p}=0.34$. As all subjects were able to perform the low-flow exhalation, the results are from the data using the HMA method.

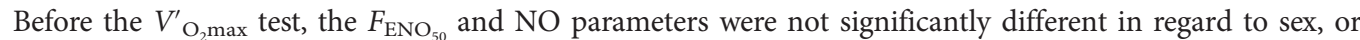
treatment with ICS and/or $\beta_{2}$-agonists. Neither were there any differences in $F_{\mathrm{ENO}_{50}}(\mathrm{p}=0.37), J_{\text {awNO }}$ $(\mathrm{p}=0.59), C_{\text {awNO }}(\mathrm{p}=0.10), D_{\text {awNO }}(\mathrm{p}=0.19)$ or $C_{\text {ANO }}(\mathrm{p}=0.71)$ between those with and those without declared asthma, as shown in table 2 . There were no statistically significant differences between those with declared allergy and those without: $F_{\mathrm{ENO}_{50}}(14(12-29) \mathrm{ppb}$ and $17(10-23) \mathrm{ppb}$, respectively) $\mathrm{p}=0.57$, $J_{\text {awNO }}\left(0.9(0.6-1.7) \mathrm{nL} \cdot \mathrm{s}^{-1}\right.$ and $\left.0.8(0.6-1.5) \mathrm{nL} \cdot \mathrm{s}^{-1}\right) \mathrm{p}=0.70, C_{\text {awNO }}(63(38-113) \mathrm{ppb}$ and $52(32-72) \mathrm{ppb})$

TABLE $2 F_{\mathrm{ENO}_{50}}$ and NO parameters expressed as median (upper and lower quartiles), before and after $V^{\prime} \mathrm{O}_{2}$ max test for all subjects together as a group and also divided into nonasthma and declared asthma groups

\begin{tabular}{|c|c|c|c|c|c|c|c|c|c|}
\hline & \multicolumn{3}{|c|}{ All (n=25) } & \multicolumn{3}{|c|}{ Nonasthma $(n=17)$} & \multicolumn{3}{|c|}{ Asthma $(n=8)$} \\
\hline$F_{\mathrm{ENO}_{50}} \mathrm{ppb}$ & $17(11-24)$ & $11(7-17)$ & $<0.001$ & $17(10-24)$ & $11(7-18)$ & $<0.001$ & $16(13-28)$ & $13(8-16)$ & 0.012 \\
\hline $\begin{array}{l}J_{\text {awNo }} \\
n L \cdot s^{-1}\end{array}$ & $\begin{array}{c}0.91 \\
(0.60-1.57)\end{array}$ & $\begin{array}{c}0.63 \\
(0.33-0.90)\end{array}$ & $<0.001$ & $\begin{array}{c}0.74 \\
(0.55-1.57)\end{array}$ & $\begin{array}{c}0.63 \\
(0.26-0.88)\end{array}$ & $<0.001$ & $\begin{array}{c}0.93 \\
(0.68-1.67)\end{array}$ & $\begin{array}{c}0.69 \\
(0.42-0.94)\end{array}$ & 0.093 \\
\hline$c_{\text {awno }} \mathrm{ppb}$ & $52(36-81)$ & $43(31-73)$ & 0.427 & $51(24-64)$ & $36(31-96)$ & 0.554 & $64(45-131)$ & $51(33-59)$ & 0.036 \\
\hline $\begin{array}{l}D_{\text {awno }} \\
\quad \mathrm{mL} \cdot \mathrm{s}^{-1}\end{array}$ & 20 (15-25) & $16(8-19)$ & 0.032 & $21(16-25)$ & $11(7-18)$ & 0.004 & $16(8-24)$ & $19(11-22)$ & 0.401 \\
\hline
\end{tabular}



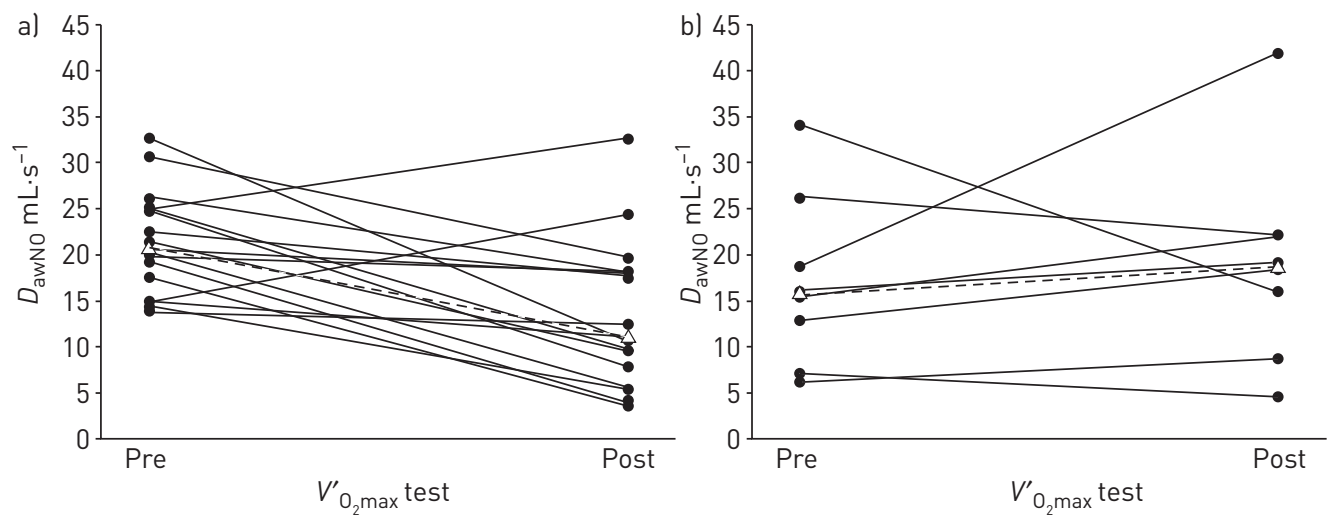

FIGURE 2 In the nonasthma group a) the NO diffusion capacity over the airway wall $\left(D_{\text {awNo }}\right)$ is decreased $(p=0.004)$ after the maximal oxygen uptake $\left(V^{\prime}{ }_{O_{2} \text { max }}\right)$ test, whereas in the asthma group b) there was no statistical change in the median value $(p=0.40)$.

$\mathrm{p}=0.46, D_{\text {awNO }}\left(19(15-26) \mathrm{mL} \cdot \mathrm{s}^{-1}\right.$ and $\left.20(15-25) \mathrm{mL} \cdot \mathrm{s}^{-1}\right) \mathrm{p}=1.0$ and $C_{\text {ANO }}(1.6(1.4-1.7) \mathrm{ppb}$ and 1.6 $(1.0-2.0) \mathrm{ppb}) \mathrm{p}=0.84$. Additionally, there were still no statistically significant differences when those with declared asthma and allergy were combined as one group and compared to those without asthma or allergy: $F_{\mathrm{ENO}_{50}}\left(18\right.$ (13-29) $\mathrm{ppb}$ and 14 (9-22) ppb respectively) $\mathrm{p}=0.17, J_{\mathrm{awNO}}\left(0.9(0.7-1.7) \mathrm{nL} \cdot \mathrm{s}^{-1}\right.$ and $\left.0.7(0.5-1.3) \mathrm{nL} \cdot \mathrm{s}^{-1}\right) \mathrm{p}=0.32, C_{\text {awNO }}(63(44-113) \mathrm{ppb}$ and $46(25-62) \mathrm{ppb}) \mathrm{p}=0.13, D_{\text {awNO }}\left(19(15-26) \mathrm{mL} \cdot \mathrm{s}^{-1}\right.$ and $\left.20(15-25) \mathrm{mL} \cdot \mathrm{s}^{-1}\right) \mathrm{p}=0.85$ and $C_{\mathrm{ANO}}(1.6(1.4,1.7) \mathrm{ppb}$ and $1.5(1.0,2.0) \mathrm{ppb}) \mathrm{p}=0.94$.

After the $V^{\prime} \mathrm{O}_{2} \max$ test, there were statistically significant differences from the baseline values in $F_{\mathrm{ENO}_{50}}$, $J_{\text {awNO}}, D_{\text {awNO }}$ and $C_{\mathrm{ANO}}($ all $\mathrm{p}<0.05)$, but not in $C_{\text {awNO }}$ for all subjects when grouped together as one group. These statistically significant differences were the same in the nonasthma group, but in the asthma group the differences could only be seen in the $F_{\mathrm{ENO}_{50}}$ and in $C_{\text {awNO }}$ values as shown in table 2. The $D_{\text {awNo }}$ decreased in the nonasthma group, but no change was found in the asthma group. The $C_{\text {awNO }}$ decreased in the asthma group, but no change was found in the nonasthma group. This is illustrated with

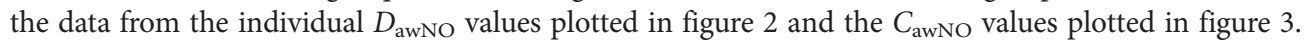

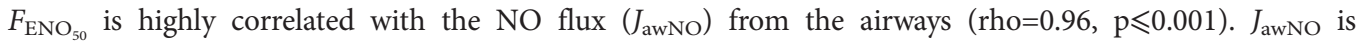

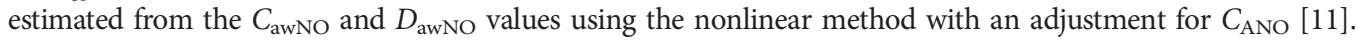
The $C_{\text {awNO }}$ has a correlation to the $F_{\mathrm{ENO}_{50}}(\mathrm{rho}=0.83, \mathrm{p} \leqslant 0.001)$, but not to the $D_{\text {awNO }}(\mathrm{rho}=-0.19, \mathrm{p}=0.37)$. In the nonasthma group the correlation between $F_{\mathrm{ENO}_{50}}$ and the $C_{\mathrm{awNO}}$ remains (rho=0.96, $\mathrm{p} \leqslant 0.001$ ), but not in the asthma group ( $\mathrm{rho}=0.50, \mathrm{p}=0.21$ ). This is possibly due to too few individuals, because when the numbers are increased with the allergy subjects, the correlation is present ( $\mathrm{rho}=0.70, \mathrm{p}=0.007)$.

\section{Discussion}

Elite junior cross-country skiers decreased their $F_{\mathrm{ENO}_{50}}$ after a $V_{\mathrm{O}_{2} \max }^{\prime}$ test. When modelling $\mathrm{NO}$ production in the lung, a difference was seen between the subjects who declared asthma and in those who
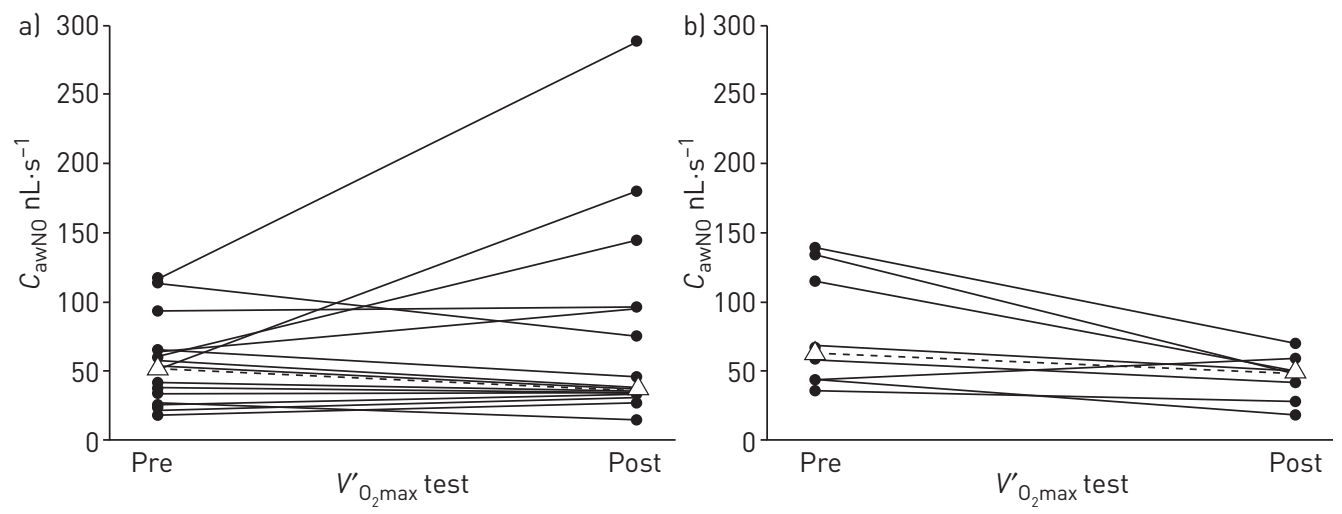

FIGURE 3 In the nonasthma group a) the NO content in the airway wall ( $\left.C_{\text {awno }}\right)$ did not change ( $\left.p=0.55\right)$ after the maximal oxygen uptake $\left(V^{\prime}{ }_{2}\right.$ max $)$ test, whereas in the asthma group b) there was a statistically significant decrease in the median value $(p=0.036)$. 
did not. The most prominent difference was in the change in the airway wall diffusion rate of NO; $D_{\text {awNO }}$. It decreased in those without asthma, whereas those with asthma and those with allergies had no change.

The $F_{\mathrm{ENO}_{50}}$ values are in line with data from healthy subjects of the same age [12]. The same NO levels were also found by SuE-CHU et al. [6] in skiers and control subjects. They used a high flow of $250 \mathrm{~mL} \cdot \mathrm{s}^{-1}$, which resulted in a $F_{\mathrm{ENO}_{250}}$ of $6(4-10) \mathrm{ppb}$ for their skiers. Using the NO parameters to retrieve the same flow, we found the $F_{\mathrm{ENO}_{250}}$ to be 5 (4-7) ppb, which is quite similar. After the $V_{\mathrm{O}_{2} \max }^{\prime}$ test, our skiers decreased their $F_{\mathrm{ENO}}$ levels by $35 \%$ and this is in line with the $34 \%$ decrease seen after a marathon race [8]. A short exercise challenge with a work intensity designed to increase the minute ventilation $40-50 \%$, gave only a $10 \%$ decrease in $F_{\mathrm{ENO}}$ [7]. This is most likely due to the difference in the degree of insult to the airways, and this should be investigated.

The most interesting finding in this study is the different response to the exercise test found in the diffusion rate of NO over the airway wall. Only among those subjects who declared asthma and/or allergy demonstrated no change in the diffusing rate of NO. This exercise test forces the subjects to breathe heavily and the dry air causes a reduction in the extravascular water in the airways. The airway mucosa becomes hyperosmotic. The hyperosmolarity in the airway epithelial cells, which is due to cell shrinkage, releases mediators that may directly or indirectly increase the airway blood flow [5]. These mediators may also be responsible for the EIB. After cell shrinkage, there is a regulatory cell volume increase in healthy subjects and a transport of sufficient water to the mucosa to overcome the hyperosmolarity of the airway surface liquid. A result of this may also be airway wall oedema, which could be the cause of the decrease in $D_{\text {awNo. }}$. In subjects with asthma, however, the rate of the transfer of water to the airway surface is slower due to airway inflammation [13]. This could possibly explain the lack of change in the $D_{\text {awNo }}$ in our subjects with asthma and allergies. In addition, the majority of our subjects with asthma were treated with $\beta_{2}$-agonists that relax the bronchial smooth muscles and prevent EIB. $\beta_{2}$-agonists can also increase the rate of water transport to the airway surface by stimulating chloride ion secretion on the apical surface of the of epithelial cells [14]. Hence, the formation of oedema is prevented. The overuse of short-acting $\beta_{2}$-agonists, which has recently been demonstrated among persons with asthma, is shown to be associated with an increased risk for exacerbations and asthma related mortality [15].

Persons with allergic asthma and rhinitis have an increased $D_{\text {awNo }}$ and $C_{\text {awNo }}$ [16]. In our skiers, we

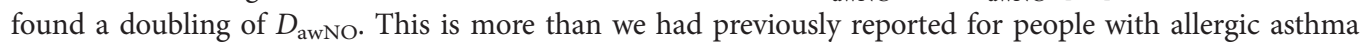
$[16,17]$. Additionally, the $C_{\text {awNo }}$ was half as much as in a healthy population [18]. In EIB, there is an increase of inflammatory cells and remodelling of the airway [19]. The inflammatory cells do not seem to be activated in athletes [5], which is a probable refection of the low NO content in the airway walls of our

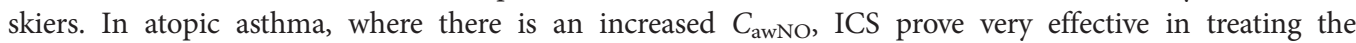
inflammation. Treatment guidelines for asthma recommend the combination of a $\beta_{2}$-agonist together with ICS. The interpretation from the results obtained with our young skiers is that they do not have inflammation of the airway wall. Therefore, they will not benefit from treatment with an anti-inflammatory drug. A lack of response to ICS by skiers has been shown by SuE-CHu et al. [20]. ICS treatment does not affect the $D_{\text {awNO }}$ [21], only the $C_{\text {awNO }}$. This explains why, for persons receiving ICS treatment for atopic asthma, the $F_{\mathrm{ENO}_{50}}$ level barely reaches the reference values and thereby a risk for over treatment with ICS exists. $F_{\mathrm{ENO}_{50}}$ is the product of $D_{\mathrm{awNO}}$ and $C_{\text {awNO }}$ with adjustment for $C_{\mathrm{ANO}}$ [11]. A high $F_{\mathrm{ENO}_{50}}$ can be due to an increase in either $D_{\mathrm{awNO}}$ or $C_{\mathrm{awNO}}$. An individual's optimal $F_{\mathrm{ENO}_{50}}$ can therefore be calculated when the level of $D_{\text {awNO }}$ is taken into account [22]. In our skiers, the $D_{\text {awNo was }}$ increased and the $C_{\mathrm{awNO}}$ was low. Hence, their $F_{\mathrm{ENO}_{50}}$ levels were not different from those found among the healthy controls. This does not mean, however, that their airways are unaffected by their strenuous training and competitions in cold dry air.

There are limitations to our study that need addressing. We did not test the skiers for bronchial hyperreactivity and did not perform lung function tests. Since we did not have access to the subject's medical records, we could not examine them and we could not determine the asthma phenotype among those who declared having physician-diagnosed asthma. Also, we do not know how adherent the subjects with asthma were to their anti-inflammatory therapy. This additional information may have been useful when we were interpreting our NO results. The NO analysis could have been made with different time intervals, but the subjects needed to stabilise their breathing to be able to perform the different flows for the extended NO analysis. Additionally, the testing may have benefited from a third measurement, but the skiers' time was too limited.

In summary, we have shown that elite junior cross-country skiers included in the current study have an increase in the diffusion capacity of NO over the airway wall. Such an increase has been found in subjects with allergic asthma together with an elevated content of NO in the airway wall. The skiers did not have an elevated $C_{\text {awNO}}$, which indicates an absence of inflammation in the airway wall. Modelling of lung NO 
production clearly shows that the asthma among our skiers is distinct from the allergic asthma in nonathletes and points to the need for an analysis of the airway inflammation in skiers before ICS are prescribed.

Acknowledgements: The authors wish to thank Robin Quell for proofreading and editing this manuscript.

Authors' contributions: M. Högman, L. Wedholm, T. Carlsson, M. Carlsson and M. Tonkonogi participated in the study design. M. Högman and L. Wedholm collected and, together with T. Carlsson, M. Carlsson and M. Tonkonogi, analysed the data. M. Högman prepared the initial draft. All authors have discussed and adjusted the draft, and have read and approved the final manuscript.

Conflict of interest: None declared.

\section{References}

1 Kippelen P, Fitch KD, Anderson SD, et al. Respiratory health of elite athletes - preventing airway injury: a critical review. Br J Sports Med 2012; 46: 471-476.

2 Norqvist J, Eriksson L, Söderström L, et al. Self-reported physician-diagnosed asthma among Swedish adolescent, adult and former elite endurance athletes. J Asthma 2015; 52: 1046-1053.

3 Lennelöv E, Irewall $\mathrm{T}$, Naumburg $\mathrm{E}$, et al. The prevalence of asthma and respiratory symptoms among cross-country skiers in early adolescence. Can Respir J 2019; 2019: 1514353.

4 Carlsen KH, Anderson SD, Bjermer L, et al. Exercise-induced asthma, respiratory and allergic disorders in elite athletes: epidemiology, mechanisms and diagnosis: part I of the report from the Joint Task Force of the European Respiratory Society (ERS) and the European Academy of Allergy and Clinical Immunology (EAACI) in cooperation with GA2LEN. Allergy 2008; 63: 387-403.

5 Anderson SD, Kippelen P. Airway injury as a mechanism for exercise-induced bronchoconstriction in elite athletes. J Allergy Clin Immunol 2008; 122: 225-235.

6 Sue-Chu M, Henriksen AH, Bjermer L. Non-invasive evaluation of lower airway inflammation in hyper-responsive elite cross-country skiers and asthmatics. Respir Med 1999; 93: 719-725.

7 De Gouw HW, Marshall-Partridge SJ, Van Der Veen H, et al. Role of nitric oxide in the airway response to exercise in healthy and asthmatic subjects. J Appl Physiol (1985) 2001; 90: 586-592.

8 Thornadtsson A, Drca N, Ricciardolo F, et al. Increased levels of alveolar and airway exhaled nitric oxide in runners. Ups J Med Sci 2017; 122: 85-91.

9 Horvath I, Barnes PJ, Loukides S, et al. A European Respiratory Society technical standard: exhaled biomarkers in lung disease. Eur Respir J 2017; 49: 1600965.

10 Poole DC, Wilkerson DP, Jones AM. Validity of criteria for establishing maximal $\mathrm{O}_{2}$ uptake during ramp exercise tests. Eur J Appl Physiol 2008; 102: 403-410.

11 Högman M, Thornadtsson A, Hedenstierna G, et al. A practical approach to the theoretical models to calculate NO parameters of the respiratory system. J Breath Res 2014; 8: 016002.

12 Jacinto T, Malinovschi A, Janson C, et al. Evolution of exhaled nitric oxide levels throughout development and aging of healthy humans. J Breath Res 2015; 9: 036005.

13 Anderson SD, Daviskas E. The mechanism of exercise-induced asthma is. J Allergy Clin Immunol 2000; 106 453-459.

14 Nadel JA, Widdicombe JH, Peatfield AC. Regulation of airway secretion, ion transport, and water movement. In: Fishman AP, Fisher AB, eds. Handbook of Physiology: The Respiratory System, 1. Bethesda, The American Physiological Society, 1985; pp. 419-445.

15 Nwaru BI, Ekström M, Hasvold P, et al. Overuse of short-acting beta ${ }_{2}$-agonists in asthma is associated with increased risk of exacerbation and mortality: a nationwide cohort study of the global SABINA programme. Eur Respir J 2020; 55: 1901872.

16 Högman M, Malinovschi A, Norbäck D, et al. Added value with extended NO analysis in atopy and asthma. Clin Physiol Funct Imaging 2011; 31: 294-299.

17 Högman M, Holmkvist T, Wegener T, et al. Extended NO analysis applied to patients with COPD, allergic asthma and allergic rhinitis. Respir Med 2002; 96: 24-30.

18 Högman $\mathrm{M}$, Thornadtsson A, Liv $\mathrm{P}$, et al. Effects of growth and aging on the reference values of pulmonary nitric oxide dynamics in healthy subjects. J Breath Res 2017; 11: 047103.

19 Karjalainen EM, Laitinen A, Sue-Chu M, et al. Evidence of airway inflammation and remodeling in ski athletes with and without bronchial hyperresponsiveness to methacholine. Am J Respir Crit Care Med 2000; 161: 2086-2091.

20 Sue-Chu M, Karjalainen EM, Laitinen A, et al. Placebo-controlled study of inhaled budesonide on indices of airway inflammation in bronchoalveolar lavage fluid and bronchial biopsies in cross-country skiers. Respiration 2000; 67: 417-425.

21 Silkoff PE, Sylvester JT, Zamel N, et al. Airway nitric oxide diffusion in asthma. Role in pulmonary function and bronchial responsiveness. Am J Respir Crit Care Med 2000; 161: 1218-1228.

22 Högman $\mathrm{M}$, Meriläinen $\mathrm{P}$. Guidance for a personal target value of $\mathrm{F}_{\mathrm{E}} \mathrm{NO}$ in allergic asthma: case report and theoretical example. Ups J Med Sci 2013; 118: 59-61. 